\title{
Knowledge of oral cancer and preventive attitudes of Spanish dentists. Primary effects of a pilot educational intervention
}

\author{
Juan Seoane-Lestón ${ }^{1,3}$, Jose Velo-Noya ${ }^{1}$, Samann Warnakulasuriya ${ }^{2}$, Pablo Varela-Centelles ${ }^{1}$, Antonio \\ Gonzalez-Mosquera ${ }^{1}$, Manuel-Alfonso Villa-Vigil ${ }^{3}$, Francisco Rodríguez-Lozano ${ }^{3}$, Pedro Diz-Dios ${ }^{1}$
}

\footnotetext{
${ }^{1}$ Stomatology Department. School of Medicine and Dentistry. University of Santiago de Compostela. Santiago de Compostela. Spain

${ }^{2}$ Department of Oral Medicine and Pathology, WHO Collaborating Centre for Oral Cancer and PreCancer, Guy’s, King's \& St. Thomas' Dental Institute. Denmark Hill Campus. London. UK

${ }^{3}$ General Dental Council. Madrid. Spain
}

Correspondence:

Cantón Grande $n^{\circ} 5$, apto. $1^{\circ} \mathrm{E}$

E-15003 A Coruña Spain

juanmanuel.seoane@usc.es

Received: $25 / 04 / 2009$

Accepted: 20/09/2009

Seoane-Lestón J, Velo-Noya J, Warnakulasuriya S, Varela-Centelles P, Gonzalez-Mosquera A, Villa-Vigil MA, Rodríguez-Lozano F, Diz-Dios P. Knowledge of oral cancer and preventive attitudes of Spanish dentists. Primary effects of a pilot educational intervention. Med Oral Patol Oral Cir Bucal. 2010 May 1;15 (3):e422-6.

http://www.medicinaoral.com/medoralfree01/v15i3/medoralv15i3p422.pdf

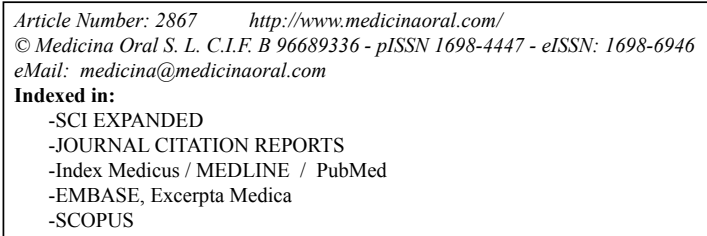

\begin{abstract}
Objective: To assess the knowledge and preventive attitudes that Spanish dentists have towards oral cancer, before and after an educational intervention.

Methods: A quasi-experimental study based on a nationwide intervention. All Spanish dentists were offered an on-site course on oral cancer. An individual questionnaire was administered before and after attending the course. The main outcome measures were systematic examination of the oral cavity, promotion of healthy habits and knowledge of clinical aspects.

Results: 440 GDPs entered the study. Age: $40.7 \pm 10.7$, range 21-74. Professional experience: $13.9 \pm 8.9$ years, range $0-45$. Of those who participated in the study, $53.1 \%$ had never attended a course on oral cancer, $72.4 \%$ stated that they perform a systematic examination of the oral mucosa, $88.2 \%$ provided systematic counselling on tobacco cessation, and 54.7\% reported that they did the same for alcohol. In addition, 32.3\% advised patients to eat fruits and vegetables high in antioxidants.

Professional experience was significantly associated with oral mucosa systematic examination $(t=2.9 ; p=0.003)$, advice on alcohol consumption ( $t=5.0 ; p=0.000)$, and on fruit and vegetable intake $(t=5.1 ; p<0.001)$. None of these practices were specifically associated with knowledge on oral cancer. All areas of knowledge examined showed statistically significant improvement after the educational intervention.

Conclusions: The intervention appears to have improved the GDP's knowledge, confirming the importance of this national campaign.
\end{abstract}

Key words: Oral cancer, prevention, dentists, continuing dental education. 


\section{Introduction}

Oral cancer is a global health problem with increasing rates of incidence and rising mortality rates (1), particularly in certain regions of Europe (France, Hungary, Spain and Croatia), and in South East Asia and Brazil. Oral cancer also has one of the lowest survival rates that remain unaffected despite recent therapeutic advances, mainly because of late presentation due to delays in the diagnosis (period elapsed since the first symptom or sign until the definitive diagnosis). Almost half of the oral cancers are diagnosed at advanced stages, with low 5 -year survival rates (20-50\%), depending on tumour sites (2). In this sense, early diagnosis is a foremost step for reducing cancer mortality.

Taking this into account, different professional organizations both in USA and Europe, have carried out campaigns aimed at increasing information and awareness among both public and dentists about the challenge of oral cancer (3-5). Dental professional organizations can make constructive contributions towards achieving further improvements in professional involvement in prevention, early detection, and management of oral cancer and premalignant disease $(3,5)$. The focus for such actions should be a need for increasing their own oral cancer educational programs for the public and healthcare providers, emphasizing regular clinical oral examination (screening) and providing guidelines for investigation (including biopsy). The criteria for referral of patients with suspicious lesions have also been suggested by oral cancer experts $(3,5)$.

The objective of this study was to assess Spanish GDPs' knowledge and preventive attitudes towards oral cancer before and after an educational pilot intervention.

\section{Subjects and Methods}

During 2007, a nationwide campaign for prevention and early diagnosis of oral cancer ("Campaña Nacional de Prevención y diagnóstico Precoz del Cáncer Oral”) was completed by the General Dental Council of Spain and supported by the public (Regional Health Authorities) and private (Spanish Association Against Cancer) institutions. This week-long campaign (26-30 March 2007) was aimed at informing and alerting both the public and dentists about the oral cancer problem, particularly issues related to late diagnosis and challenges.

In order to increase preventive attitudes and knowledge on oral cancer and precancer among Spanish dentists, a 4 hour updating course was designed by a panel of experts. This course was focused on the following topics: Size of the problem (epidemiology and identification of risk groups), preventive behaviours (systematic examination of oral mucosa, tobacco and alcohol cessation and encouragement of high vegetable consumption), clinical manifestations of oral cancer and precancer (visual diagnosis), biopsy of suspicious lesions (video on indications, technique and materials), guidelines and protocols for referral of patients with precancer and suspicious lesions. This course was administered before launching the campaign (February 2007) at all Provincial Dental Councils in Spain. Moreover -and as part of the campaign- every registered dentist in the country received one of the 21,500 copies of a small book and a DVD supported atlas on oral cancer.

With the intention of assessing the effect of the intervention, and to guide future educational strategies, a pilot study was designed. This quasi-experimental study (pre- versus post- intervention) was based upon a 19 items self-applied questionnaire to be filled at the Provincial Dental Councils.

The questions used were broadly grouped into three parts:

1. GDPs profiling questions (e.g. age, gender and professional experience; 4 items).

2. Questions concerning general preventive attitudes towards oral cancer (e.g. systematic examination of the oral cavity, alcohol, tobacco, and fruits and vegetable consumption; 5 items).

3. Specific questions about knowledge on clinical aspects of oral cancer and precancer, oral biopsies of suspicious lesions and referral of patients with high index of clinical suspicion (10 test items).

A copy of the questionnaire is available on request from the authors.

To compare the profile of the study group with Spanish dentists' mean age and years of professional experience these data were retrieved from records held by the Spanish General Dental Council (SGDC).

Statistical analysis was performed by means of a SPSS +11.0 statistical package. Pearson's chi-square was used to compare proportions and Student's t test for comparing means after assessing their conditions of use. The level of significance chosen was $5 \%$. Confidence intervals around the mean and the proportions were calculated by the statistical program Epidat 3.1.

\section{Results}

The convenience sample studied included 440 GDPs from 14 dental councils from all over Spain (including Balearic and Canary islands) who attended the on-site course. Their mean age was $40.7 \pm 10.7$ years, ranging from 21 to 74. Professional experience distributed along a wide range of years ( 0 to 45 ), with a mean $13.9 \pm 8.9$ years and a median of 14 years. On comparison, the mean age of the Spanish dentists was $42.4 \pm 11.9$ (95\% CI between study sample and all Spanish dentists $=0.7-$ 2.7) and the mean of years of professional experience was $12 \pm 9$ years with a median of 12 years $(95 \%$ CI between study sample and all Spanish dentists $=-2.76$ $-1.03)$.

A high proportion of the participants (53.1\%) had never 
attended a continuous education course related to the topic of oral cancer. When asked about their approach to examination of the oral mucosa, a $72.4 \%$ affirmed that they performed a systematic examination of the oral mucosa on every patient seen in practice. An $88.2 \%$ stated that they provided systematic counselling on tobacco cessation and a $54.7 \%$ did the same about alcohol. Only a $32.3 \%$ advised their patients to eat fruit and vegetables with high antioxidant contents.

Professional experience was significantly associated with preventive attitudes about systematic examination of the oral mucosa $(\mathrm{t}=2.9 ; \mathrm{p}=0.003)$, advice on alcohol consumption $(\mathrm{t}=5.0 ; \mathrm{p}<0.001)$, and advice on fruit and vegetable intake $(t=5.1 ; \mathrm{p}<0.001)$. However, none of these preventive attitudes was significantly associated with GDPs' knowledge on oral cancer.

All areas of knowledge examined showed statistically significant improvement after the educational intervention. They included: knowledge on the incidence of oral cancer and lowered risks by vegetable intake, clinical aspects and potential for malignancy of oral precancer, clinical characteristics of oral cancer, indications for biopsy and reference criteria of lesions that are suspected to be malignant.

When GDPs' knowledge on oral cancer and precancer was grouped on a single variable the number of correct answers (range 1 to 10), a significant difference could be identified between baseline (pre-intervention mean= 4.8) and post educative intervention (mean= 7.4); $(\mathrm{t}=$ 20.2; $\mathrm{p}<0.001)$. These findings are detailed on Table 1 . Compared to their knowledge on oral cancer, GDPs' were found to have a better knowledge on oral precancerous conditions at both baseline and post intervention (Table 2).

Table 1. Description of GDPs' knowledge of oral cancer and precancer by specific areas. Baseline and post-educational intervention.

\begin{tabular}{|c|c|c|c|c|}
\hline Knowledge on oral cancer and precancer & $\begin{array}{c}\text { GDPs } \\
(\mathrm{n}=440) \\
\text { Baseline } \\
\text { n }(\%)\end{array}$ & $\begin{array}{c}\text { GDPs }(n=440) \\
\text { Post-intervention } \\
\text { n (\%) }\end{array}$ & $\chi^{2}$ & $\mathbf{p}$ \\
\hline OC incidence in Spain & $157(35.8)$ & $356(81.1)$ & 185.6 & $<0.001$ \\
\hline $\begin{array}{l}\text { Effect of vegetable consumption on the reduc- } \\
\text { tion of OC incidence }\end{array}$ & $82(18.6)$ & $270(61.3)$ & 167.6 & $<0.001$ \\
\hline $\begin{array}{l}\text { Potential for malignant transformation of pre- } \\
\text { cancerous lesions }\end{array}$ & $142(32.3)$ & $332(75.6)$ & 165.5 & $<0.001$ \\
\hline Clinical aspects of oral leukoplakias & $343(78.1)$ & $376(85.6)$ & 8.3 & $<0.001$ \\
\hline Clinical aspects of OLP & $316(72)$ & $351(80)$ & 9.0 & 0.011 \\
\hline Clinical aspects of actinic cheilitis & $231(52.6)$ & $315(71.8)$ & 35.2 & $<0.001$ \\
\hline Clinical features of OC & $251(57.2)$ & $291(66.3)$ & 7.7 & 0.005 \\
\hline Main sites for oral OC & $201(45.8)$ & $377(85.9)$ & 157.1 & $<0.001$ \\
\hline $\begin{array}{l}\text { Biopsy of lesions with high suspicion of malig- } \\
\text { nancy }\end{array}$ & $76(17.3)$ & $194(44.2)$ & 74.4 & $<0.001$ \\
\hline $\begin{array}{l}\text { Criteria for referral of patients with suspicious } \\
\text { lesions }\end{array}$ & 364 (82.9) & $400(91.1)$ & 13.5 & 0.001 \\
\hline
\end{tabular}

OC: Oral Cancer; OLP: Oral Lichen Planus

Table 2. Description of GDPs' knowledge of precancer versus oral cancer. Baseline and post-educational intervention.

\begin{tabular}{|c|c|c|c|c|c|}
\hline $\begin{array}{c}\text { Knowledge of oral cancer } \\
\text { and precancer }\end{array}$ & \multicolumn{2}{|c|}{$\begin{array}{l}\text { Oral precancer } \\
\text { n }(\%)\end{array}$} & $\begin{array}{l}\text { Oral cancer } \\
\mathrm{n}(\%)\end{array}$ & $\begin{array}{l}\mathrm{CI}(95 \%) \text { for the diference bet- } \\
\text { wen precancer and oral cancer }\end{array}$ & $\mathrm{p}$ \\
\hline \multirow{3}{*}{ Pre-intervention } & oral leukoplakia & $343(78.1)$ & \multirow{3}{*}{$251(57.2)$} & $0.270-0.146$ & $<0.001$ \\
\hline & oral lichen planus & $316(72)$ & & $0.212-0.083$ & $<0.001$ \\
\hline & actinic cheilitis & $231(52.6)$ & & $0.021-0.113$ & 0.1 \\
\hline \multirow{3}{*}{ Post-intervention } & oral leukoplakia & $376(85.6)$ & \multirow{3}{*}{$291(66.3)$} & $0.250-0.135$ & $<0.001$ \\
\hline & oral lichen planus & $351(80)$ & & $0.197-0.760$ & $<0,001$ \\
\hline & actinic cheilitis & $315(71,8)$ & & $0.118-0.008$ & 0.06 \\
\hline
\end{tabular}




\section{Discussion}

There are a number of limitations to our study that we ought to report. In general, the Statistics community frowns on convenience samples. It will often difficult to generalize the results of a convenience sample to any population that has practical relevance. Still, convenience samples can provide useful information, especially in a pilot study. To interpret the findings from a convenience sample properly, it has to be characterized (usually in a qualitative sense) how the sample would differ from an ideal sample that was randomly selected. To avoid this bias and to ensure a representative sample, information about age, years of practice and type of professional practice (private clinic or public health system) was obtained from the files of General Dental Council of Spain (CGOE). Using this information the sample studied was compared to the whole Spanish GDPs population. Absence of any significant differences suggested that our study sample was representative of Spanish dentists on these parameters assessed.

Another potential bias could be the inclination of the participants to acquire further knowledge about oral cancer that could not be shared by the rest of the Spanish GDPs. However, more than a half of the interviewed dentists had never previously attended an education course related to oral cancer. Moreover, this study had the limitations inherent within a cross-sectional design: in order to confirm the efficacy of this educational intervention, it will be mandatory to ascertain whether the acquisition of knowledge about oral cancer is maintained in the medium- and long-run besides determining whether it favours early diagnosis of oral cancer and precancer in a cost-benefit analysis.

Dental professionals have an important role in both, primary prevention of oral cancer by encouraging healthy lifestyles and secondary prevention by detecting oral cancer or its precursor lesions at early stages (6). In Europe, the low prevalence of oral cancer contributes to a low detection rate of new cases in population screening programmes. However, opportunistic screening involves offering patients a screen when they attend a clinic for some other, unrelated reason, particularly in general dental practice, and this approach may be costeffective (7). Such screening may be more effectively targeted to high-risk groups, particularly smokers and alcohol users in the 40-60 year old groups (7). Moreover, new educational strategies are needed to identify populations who are likely to be ignored and considered at low risk, such as younger people and non-smoking and non-drinking patients (8). Thus, the range of ages and criteria for systematic oral examination should be broadened.

Opportunistic screening by GDPs includes a systematic examination of the oral mucosa during regular dental care. In the present study, most respondents $(72.4 \%)$ de- clared to perform a systematic examination of oral soft tissues to rule out oral precancer/cancer; this percentage is close to the one reported by other authors in Europe and USA $(83-86 \%)(5,9)$. Despite this fact, the ability of the examiners to make a correct positive detection of oral cancer (sensitivity (Sn)) remains low worldwide: reported Sn scores varied from 0.4 to 1.0. The "Two weeks wait" scheme was rolled out in December 2000, for Head and Neck cancer referrals in the United Kingdom (Department of Health, 2000). An audit of this initiative indicates a high proportion of non-malignancies are referred via the fast track system to the hospitals due to low sensitivity of visual detector guidelines (10). Although the specificity (Sp) ranged from 0.31 to 0.92 , most studies show low values scored for the screening of oral cancer and precancer, which would mean that patients with oral cancer may not be adequately referred for the decisive diagnostic and treatment. In this sense, it is important for a GDP to know which kind of cases should be sent to a specialist.

Despite the fact that advice on smoking cessation, alcohol moderation and healthy eating is an essential and ethical part of the dentist role, several gaps in knowledge have been identified in GDPs' awareness of oral cancer risk factors and the application of preventive measures (11). The results of this study reveal a high proportion of Spanish GDPs (88.2\%) do take advantage of their position to advice patients on tobacco cessation. Signs of improvement on tobacco cessation activities by the UK dentists in primary care setting have also been reported (12). However, only a $54.7 \%$ of the GDPs advised on moderation of alcohol consumption, even when a major role has been attributed to alcohol for the increased incidence of oral cancer (13) together with its identification as an independent risk factor for oral premalignant lesions, regardless of the beverage type or drinking patterns. Moreover, recommendations to reduce alcohol intake have the potential to reduce incidence of oral cancer and oral premalignant lesion in non-smokers and smokers alike. Contrary to earlier impressions, patients do readily accept alcohol screening and alcohol counselling by the dentist (14).

Previous reports have used survey-type questionnaires to evaluate dentists' ability to diagnose and make proper referral for treatment of oral and oropharyngeal cancers (15). These reports provide data on perceptions and knowledge regarding oral cancer, and also find gaps of knowledge among their respondents particularly underscoring the incidence of oral cancer and their perceived potential for malignant transformation of some precancerous lesions.

Regardless of the existence of studies that provide further support to the beneficial effects of high intake of vegetables and fruits on reducing the risk of developing cancers of the oral cavity, particularly among current 
smokers and heavy alcohol drinkers (6), Spanish dentists at baseline had little knowledge of the advantages of fruits and vegetables in reducing risks for oral cancer. The educational program appears to have improved this knowledge from a low $18 \%$ to a high $61 \%$, confirming the value of the national campaign aimed at GDPs.

Recent reports in the USA (16) and Europe (17), describe an increasing proportion of GDPs who offer oral biopsy either on a routine or on a selective bases. However, their knowledge on identification of biopsy sites or on biopsy techniques (incisional versus excisional) has not been adequately investigated. Incisional biopsies of lesions suspicious of malignancy represent a more realistic approach for GDPs, but incisional biopsies at times may lead to underdiagnosis due to sampling errors (18). On the other hand, excisional biopsies undertaken by GDPs made without oncological consideration of lesions suspected to be malignant would allow microscopic tumour remnants to remain in situ and causes destruction of the margins of the lesion, and thus making a re-excision necessary and eventually neck treatment mandatory.

Even though this intervention is considered positive, in order to reduce professional delay in oral cancer diagnosis, it seems mandatory to continue with the educational efforts aimed at training GDPs to perform a full mouth examination in order to detect potentially malignant and malignant disorders, with high sensitivity and specificity. The access to and the kind of healthcare system in a particular country are also relevant, particularly the referral system. The design of a simple, clear, fail-safe referral scheme may diminish greatly the length of the delay (19).

Future directions in this field should consider including education in this field as a regular part of continuing professional development (5) and the creation of international cooperation networks and electronic websites containing worldwide information to ease professional training on this topic.

In conclusion, the educational intervention appears to have improved the GDPs' knowledge, confirming the value of this national campaign. The results of this study however have a preliminary nature and need further confirmation following a longitudinal design.

\section{References}

1. Gillison ML. Current topics in the epidemiology of oral cavity and oropharyngeal cancers. Head Neck. 2007;29:779-92.

2. Brandizzi D, Chuchurru JA, Lanfranchi HE, Cabrini RL. Analysis of the epidemiological features of oral cancer in the city of Buenos Aires. Acta Odontol Latinoam. 2005;18:31-5.

3. Warnakulasuriya KA, Johnson NW. Dentists and oral cancer prevention in the UK: opinions, attitudes and practices to screening for mucosal lesions and to counselling patients on tobacco and alcohol use: baseline data from 1991. Oral Dis. 1999;5:10-4.

4. Stahl S, Meskin LH, Brown LJ. The American Dental Association's oral cancer campaign: the impact on consumers and dentists. J Am Dent Assoc. 2004;135:1261-7.
5. McLeod NM, Saeed NR, Ali EA. Oral cancer: delays in referral and diagnosis persist. Br Dent J. 2005;198:681-4.

6. Sánchez MJ, Martínez C, Nieto A, Castellsagué X, Quintana MJ, Bosch FX, et al. Oral and oropharyngeal cancer in Spain: influence of dietary patterns. Eur J Cancer Prev. 2003;12:49-56.

7. Conway DI. To screen or not to screen? Is it worth it for oral cancer? Evid Based Dent. 2006;7:81-2.

8. Farshadpour F, Hordijk GJ, Koole R, Slootweg PJ. Non-smoking and non-drinking patients with head and neck squamous cell carcinoma: a distinct population. Oral Dis. 2007;13:239-43.

9. Yellowitz JA, Goodman HS. Assessing physicians' and dentists' oral cancer knowledge, opinions and practices. J Am Dent Assoc. 1995;126:53-60.

10. Singh P, Warnakulasuriya S. The two-week wait cancer initiative on oral cancer; the predictive value of urgent referrals to an oral medicine unit. Br Dent J. 2006;201:717-20.

11. Kujan O, Duxbury AJ, Glenny AM, Thakker NS, Sloan P. Opinions and attitudes of the UK's GDPs and specialists in oral surgery, oral medicine and surgical dentistry on oral cancer screening. Oral Dis. 2006;12:194-9.

12. Johnson NW, Lowe JC, Warnakulasuriya KA. Tobacco cessation activities of UK dentists in primary care: signs of improvement. Br Dent J. 2006;200:85-9.

13. Schlecht NF, Pintos J, Kowalski LP, Franco EL. Effect of type of alcoholic beverage on the risks of upper aerodigestive tract cancers in Brazil. Cancer Causes Control. 2001;12:579-87.

14. Miller PM, Ravenel MC, Shealy AE, Thomas S. Alcohol screening in dental patients: the prevalence of hazardous drinking and patients' attitudes about screening and advice. J Am Dent Assoc. 2006;137:1692-8.

15. Yellowitz JA, Horowitz AM, Drury TF, Goodman HS. Survey of U.S. dentists' knowledge and opinions about oral pharyngeal cancer. J Am Dent Assoc. 2000;131:653-61.

16. Colella G, Gaeta GM, Moscariello A, Angelillo IF. Oral cancer and dentists: knowledge, attitudes, and practices in Italy. Oral Oncol. 2008;44:393-9.

17. Seoane J, Warnakulasuriya S, Varela-Centelles P, Esparza G, Dios PD. Oral cancer: experiences and diagnostic abilities elicited by dentists in North-western Spain. Oral Dis. 2006;12:487-92.

18. Pentenero M, Carrozzo M, Pagano M, Galliano D, Broccoletti R, Scully C, et al. Oral mucosal dysplastic lesions and early squamous cell carcinomas: underdiagnosis from incisional biopsy. Oral Dis. 2003;9:68-72.

19. Reed M, Claffey N, Allen B, Beeley J, Beemsterboer P, Carrassi A, et al. 2.3 Towards global convergence of education, training, quality, outcome and assessment. Eur J Dent Educ. 2002;6 Suppl 3:7883. 